\title{
O BEM-ESTAR DE CUIDADORES DE CRIANÇAS TÍPICAS E CRIANÇAS COM NECESSIDADES ESPECIAIS
}

\author{
THE WELL-BEING OF CAREGIVERS OF TYPICAL CHILDREN AND CHILDREN WITH \\ SPECIAL NEEDS OF CARE
}

\author{
EL BIENESTAR DE LOS/AS CUIDADORES/AS DE NIÑOS/AS CON Y SIN \\ NECESIDADES ESPECIALES
}

\section{Lucieny Almohalha', Victoria Pereira ${ }^{2}$}

\begin{abstract}
RESUMEN
El presente trabajo es sobre un estudio exploratorio descriptivo de abordaje cualitativo, realizado en un ambulatorio de pediatría de una universidad federal de la región del Triángulo Minero, Brasil. Tuvo como objetivo, investigar el bienestar de cuidadores de niños típicos y niños con necesidades especiales de salud, desde el nacimiento hasta los 12 años de edad. Participaron de la pesquisa 20 cuidadores en el período de noviembre de 2018 hasta mayo de 2019. Los instrumentos de recolección de datos fueron un cuestionario cerrado y una entrevista semiestructurada. El tratamiento de los datos se obtuvo a través del análisis de contenido temático de Bardin. El estudio correspondió la resolución 466/12 del Consejo Nacional de Salud, fue aprobada por el Comité de Ética en Pesquisa, y por los participantes a través del Termo de Consentimiento Libre y Esclarecido. Por medio de la lectura, análisis y la organización de las informaciones obtenidas, fueron elaboradas tres categorías temáticas: 1) El impacto de la maternidad en el cotidiano de los cuidadores; 2) Relación bienestary apoyo social; 3) El bienestar influenciado por la condición de salud del niño. Se concluye que, las alteraciones en el cotidiano materno, en las posibilidades de elección en la vida diaria y del apoyo social recibido o no, irán interferir en el bienestartanto de los cuidadores de niños típicos cuanto de niños con necesidades especiales, siendo que estas sufren mayor impacto en su bienestar, con interferencia en las esferas psicológica, física, social y económica.
\end{abstract}

\section{PALABRAS CLAVES}

Cuidadores, relaciones madre-hijo, autocuidado, terapia ocupacional.

\begin{abstract}
To carry out this study, an exploratory-descriptive and qualitative approach was used, in a pediatric outpatient facility from a federal university of Triângulo Mineiro's region, Brazil. The main goal of the following study is to investigate the well-being of caregivers of typical children, and with special needs of care, from birth to the age of 12 years old. Twenty caregivers participated of this research between November 2018 to May 2019. The data collection instruments were a questionnaire and a semi-structured interview, and the collected information was processed through a Bardin themed analysis. The study followed the 466/12 Resolution of the National Health Council and was approved by the Research Ethics Committee of the same University and by the participants through a Consent Form. After reading, analyzing and organizing data, three themed categories were created: 1) The motherhood impact on the caregiver's routine; 2) Relation between well-being and social support; 3)
\end{abstract}

1 Graduanda do Curso de Terapia Ocupacional da Universidade Federal do Triângulo Mineiro - UFT. E-mail: vicpjcordeiro@gmail.com

2 Profa ${ }^{2} r^{a}$ do Curso de Terapia Ocupacional da Universidade Federal do Triângulo Mineiro - UFTM. https://orcid.org/0000-0003-01271032. E-mail: lucieny.almohalha@uftm.edu.br. Endereço para correspondência: Universidade Federal do Triângulo Mineiro. Instituto de Ciências da Saúde. Departamento de Terapia Ocupacional. Centro de Pesquisas Professor Aluízio Rosa Prata, Rua Vigário Carlos, nº 100, Bairro Abadia.4º piso. sala 414. Uberaba/MG. CEP: 38025-350. 
The child's health condition's influence on the well-being of the caregiver. It was concluded that the changes in the maternal routine, the choices in everyday life and existing or nonexisting social support, will interfere in the well-being of the caregivers and the children, both typical and with special needs; it is important to note that the ones with children with special needs will suffer greater impact in all aspects of life, such as psychological, physical, social and economic.

\section{KEYWORDS}

Caregivers, mother-child relations, self-care, occupational therapy.

Fecha Recepción: 12/07/2019

Fecha Aceptación: 02/12/2020

\section{INTRODUÇÃO}

O avanço tecnológico na área de terapia intensiva neonatal e pediátrica tem contribuído para a diminuição da morbimortalidade infantil de crianças com doenças crônicas e/ou incapacitantes (Zamberlan, 2014). Como consequência deste progresso, surgiu um grupo de crianças clinicamente frágeis e dependentes de tecnologia e/ou cuidados de saúde, denominadas na literatura nacional como Crianças com Necessidades Especiais de Saúde - CRIANES (Silveira \& Neves, 2012).

Devido à fragilidade clínica e a vulnerabilidade de saúde, a criança com necessidades especiais decorrentes de doença crônica demanda cuidados de natureza temporária ou permanente, dependência contínua dos serviços de saúde e de diferentes profissionais, e ainda necessidades intermitentes de cuidados maternos (Neves \& Cabral, 2008). Assim, essa criança requer cuidados específicos mesmo no pós-alta hospitalar, por isso torna-se imprescindível que os profissionais de saúde atentem para as suas necessidades e de suas famílias, a fim de que haja continuidade nos cuidados desenvolvidos em âmbito domiciliar (Silveira \& Neves, 2012).

Cuidadores desempenham um papel fundamental na manutenção da vida dos indivíduos doentes ou com condições crônicas de saúde que necessitam de cuidados intermitentes. Entretanto, estudos relatam que inerentes à prestação de cuidados, a experiência de cuidar de um familiar doente pode acarretar uma grande sobrecarga emocional, física e financeira, afetando a qualidade de vida, pois cuidar de um familiar exige disponibilidade, tempo e dedicação (Delalibera, Presa,
Barbosa \& Leal, 2015) assim como adequação da rotina de trabalho. A família tem um papel importante no cuidado da criança, sendo responsável pelo bem-estar físi$\mathrm{co}$, emocional e social, além de ser no âmbito familiar que a criança tem seu referencial; portanto, a inclusão da família em seu tratamento é de extrema importância para o seu desenvolvimento (Comaru \& Monteiro, 2008; Silveira \& Neves, 2012).

Em cada fase do desenvolvimento infantil surgem diversas demandas de cuidados, muitos dos quais se assemelham àqueles de famílias com crianças em desenvolvimento típico (Minatel \& Matsukura, 2014). Contudo, famílias com filhos com necessidades especiais também enfrentam, acrescidos às demandas típicas, as exigências advindas da própria condição de deficiência da criança, pois as necessidades especiais, as dificuldades em realizar tarefas da vida diária e a maior dependência ocasionam uma sobrecarga física e psicológica aos familiares (Sprovieri \& Assumpção Junior, 2001). Pais de crianças com doenças ou condições crônicas além de restringirem o tempo pessoal dedicado a seus companheiros e amigos, também apresentam comprometimento na estabilidade emocional, qualidade de vida e na função física diária e laboral. (Goldbeck, 2006).

Segundo a revisão sistemática de Delalibera, Presa, Barbosa e Leal (2015), o apoio social, juntamente com a esperança e a capacidade do cuidador de atribuir um significado à experiência de cuidar, foram associados a menores níveis de sobrecarga na vida desses cuidadores. Cochran e Niego (1995), definiram rede de apoio social como instituições ou pessoas de fora da família que dão aos pais algum tipo de suporte, podendo ser 
material, emocional, e informação sobre cuidado e educação. Neste sentido, a rede de apoio auxiliaria na diminuição do estresse e da sobrecarga, colaborando para a melhora no bem-estar; oferecendo ainda, suporte psicológico e material para os pais, e os encorajando no exercício da maternidade (Ribas, Junior \& Valente, 2006).

Segundo Misquiatti, Brito e Assumpção (2015), a avaliação da vivência e sobrecarga do cuidador através do seu próprio ponto de vista contribui para o entendimento do real impacto que uma condição determina em sua vida, merecendo uma atenção especial por parte dos profissionais de saúde. Assim, a compreensão das interações da família com a condição da criança permite ao profissional perceber que os cuidadores familiares também precisam de cuidados e orientações para uma melhor qualidade de vida (Manoel, Teston, Waidman, Decesaro \& Marcon, 2013).

Nessa perspectiva, o objetivo desse estudo foi investigar e descrever o bem-estar dos cuidadores de crianças com desenvolvimento típico e de CRIANES a fim de entender o impacto do cuidado, as mudanças e sobrecargas na vida do cuidador por meio de sua própria percepção. Logo, esse entendimento oferece subsídios para a produção cientifica acerca desta temática, e para a assistência centrada nas reais necessidades e demandas de cuidado voltados para essas pessoas.

\section{Métodos}

Este estudo consistiu em uma pesquisa descritiva e exploratória com abordagem qualitativa, com cuidadores de crianças com desenvolvimento típico e de CRIANES do nascimento até 12 anos de idade, realizada em ambulatório de pediatria de uma universidade federal da região do triângulo mineiro, Brasil. Entende-se por cuidadores aqueles indivíduos que moram com a criança na mesma residência, aqueles que realizam os cuidados de vida diária ou cuidados com a saúde da criança, ou que permanecem diariamente com a criança.

Através desse desenho metodológico foi possível explorar e descrever características da população ou fenômeno e a relação entre variáveis (Gil, 2010), pois essa abordagem preconiza os aspectos não quantificáveis da realidade, e é centrado na compreensão e explicação da dinâmica das relações sociais. Enfoca ainda o universo de significados, motivos, aspirações, crenças, valores e atitudes que não podem ser reduzidos à operacionalização de variáveis (Minayo, 2014, p. 22).

Os dados foram obtidos a partir da aplicação de um questionário fechado e uma entrevista semiestruturada, elaborado pelas pesquisadoras com base em estudos prévios sobre a temática abordada, e analisados a partir de plotagem em tabelas do Microsoft Word versão 2010. Os dados foram analisados pela técnica de análise de conteúdo de Bardin, que proporcionou o conhecimento do significado existente por trás das palavras mencionadas ou fenômeno pesquisado. Essa metodologia ainda objetiva organizar a mensagem para confirmar os indicadores que permitem inferir sobre realidades que não sejam da mensagem (Mozzato \& Grzybovski, 2011).

As entrevistas foram heteroaplicadas com os participantes, em sala para atendimento individual no referido local de coleta e teve duração aproximada de 40 minutos. O questionário continha informações sociodemográficas como idade, sexo, naturalidade, profissão, escolaridade, estado civil, composição familiar, renda, além de dados da gestação e do parto da criança dos participantes. A entrevista englobava questionamentos acerca do manejo de tempo diário, necessidades de mudança na rotina, da relação das atividades de vida diária com as demandas de cuidado da criança, participações e desejo por envolvimento adicional de lazer, além de questões subjetivas como níveis de sobrecarga, estresse e sentimentos atuais relacionados ao papel de cuidador. Como forma de assegurar o anonimato das participantes foi utilizado código alfanumérico para cada respondente, sendo que as cuidadoras de crianças com desenvolvimento típico receberam a letra T no código (exemplo: T1) e as cuidadoras de CRIANES, a letras C (exemplo: $\mathrm{C}_{1}$ ).

A pesquisa foi realizada respeitando todas as Normas de Pesquisa Envolvendo Seres Humanos (Res. CNS 466/12) do Conselho Nacional de Saúde e foi aprovada pelo Comitê de Ética em Pesquisa Envolvendo Seres Humanos da Universidade Federal do Triângulo Mineiro, sob o protocolo 2.983.455, CAAE: 92964618.7.0000.5154, bem como aceita pelos participantes por meio da assinatura do Termo de Consentimento Livre e Esclarecido. 


\section{Resultados}

Participaram do estudo 20 cuidadores e as informações foram coletadas de novembro de 2018 a maio de 2019. Dentre os participantes, todas do sexo feminino, dez eram cuidadoras de crianças típicas e dez de CRIANES, majoritariamente eram casadas, desempregadas e do lar, com faixa etária entre 25 e 59 anos, com ensino fundamental completo, renda de 1 a 2 salários mínimos e com residência própria constituída por até 3 pessoas. A tabela 1 demonstra a caracterização dos participantes e a comparação dos dados sociodemográficos entre os cuidadores desses dois grupos de crianças.

TABELA 1. DADOS SOCIODEMOGRÁFICAS DE CUIDADORES DE CRIANÇAS TÍPICAS E DE CRIANES.

\begin{tabular}{|c|c|c|c|}
\hline VARIÁVEL & $\begin{array}{l}\text { DADOS GERAIS CUIDA- } \\
\text { DORES }(n=20) \text { em \% }\end{array}$ & $\begin{array}{l}\text { CUIDADORES DE } \\
\text { CRIANES }(\mathrm{n}=10)\end{array}$ & $\begin{array}{l}\text { CUIDADORES DE CRIANÇAS } \\
\text { TíPICAS }(\mathbf{n}=10)\end{array}$ \\
\hline \multicolumn{4}{|l|}{ PAPEL DO RESPONDENTE } \\
\hline Mãe & 85 & 8 & 9 \\
\hline Avó Materna & 15 & 2 & 1 \\
\hline \multicolumn{4}{|l|}{ FAIXA ETARIA } \\
\hline $18-24$ Anos & 25 & 2 & 3 \\
\hline $25-59$ Anos & 65 & 7 & 7 \\
\hline+60 anos & 10 & 1 & 0 \\
\hline \multicolumn{4}{|l|}{ ESCOLARIDADE } \\
\hline Analfabeto & 10 & 2 & 0 \\
\hline Ensino Fundamental & 40 & 6 & 2 \\
\hline Ensino Médio & 25 & 1 & 4 \\
\hline Ensino Superior & 20 & 0 & 4 \\
\hline Ensino Técnico & 5 & 1 & 0 \\
\hline \multicolumn{4}{|l|}{ ESTADO CIVIL } \\
\hline Solteiro & 40 & 5 & 3 \\
\hline Casado & 60 & 5 & 7 \\
\hline \multicolumn{4}{|l|}{ OCUPAÇÃO } \\
\hline Do lar & 55 & 9 & 2 \\
\hline Estudante & 5 & 0 & 1 \\
\hline Autônomo & 10 & 0 & 2 \\
\hline Vínculo empregatício & 30 & 1 & 5 \\
\hline \multicolumn{4}{|l|}{ RENDA } \\
\hline 1 salário-mínimo (BPC) & 20 & 4 & 0 \\
\hline 1 a 2 salários-mínimos & 35 & 3 & 4 \\
\hline 3 a 4 salários-mínimos & 20 & 2 & 2 \\
\hline > 5 salários-mínimos & 15 & 0 & 3 \\
\hline Sem renda fixa & 10 & 1 & 1 \\
\hline \multicolumn{4}{|l|}{ MORADIA } \\
\hline Própria & 30 & 1 & 5 \\
\hline Aluguel & 40 & 3 & 5 \\
\hline Outra (COHAB, parentes) & 30 & 6 & 0 \\
\hline \multicolumn{4}{|l|}{ No PESSOAS QUE RESIDEM } \\
\hline 1 a 2 & 5 & 1 & 0 \\
\hline 3 a 4 & 75 & 6 & 9 \\
\hline+5 & 20 & 3 & 1 \\
\hline
\end{tabular}

Fontes: Dados da Pesquisa. * Benefício de Prestação Continuada (BPC) é um benefício de renda no valor de um salário-mínimo para pessoas com deficiência. ${ }^{* *}$ Companhia de Habitação do Estado de Minas Gerais - Cohab Minas, promove o acesso a habitação de interesse social 
A caracterização e comparação dos dados de gestação e parto das CRIANES e das crianças típicas estão descritas na Tabela 2. As idades das crianças foram divididas seguindo as fases do desenvolvimento infantil de Piaget: Período Sensóriomotor (o a 2 anos); Pré-operatório Preconceitual (2 a 4 anos); Pré-operatório Intuititvo (4 a 7 anos) e Operatório Concreto (7 a 12 anos) (Bee \& Boyd, 2011).

Dentre as dez CRIANES, com um ou mais diagnósticos concomitantes, se encontram os seguintes diagnósticos: paralisia cerebral, epilepsia, microcefalia, hidrocefalia, mielomeningocele, toxoplasmose congênita, deficiência visual, calcificação cerebral, Síndrome de Dandy Walker, Síndrome de Perisylviana, Síndrome de Asperger, autismo e atraso no desenvolvimento neuropsicomotor.

A maioria das crianças nasceu à termo, permaneceu internadas por poucos dias após nascimento (até 10 dias no máximo) e suas mães não tiveram nenhuma intercorrência durante a gestação. A respeito das intercorrências ocorridas durante o parto, 50\% das crianças (8 CRIANES e 2 típicas) tiverem complicações associadas como: anóxia $(n=4)$, icterícia $(n=4)$, convulsão $(n=1)$, parada cardiorespiratória $(n=1)$, reanimação $(n=1)$, hemorragia periventricular $(n=1)$, sepse $(n=1)$; alimentação por sonda $(n=2)$ e transfusão sanguínea $(n=2)$.

Um fato observado, foi a ausência das notas do Índice de Apgar em 55\% das carteiras de nascimento/vacinação, referido pelas cuidadoras. O estudo de Ermel e Grave (2011) menciona a importância do referido teste para a avaliação da vitalidade do recém-nascido e esclarece que a nota do quinto minuto é considerada importante para previsão de prognóstico da saúde e desenvolvimento do bebê. Ou seja, uma nota mais baixa no primeiro minuto não é tão importante quando comparada a uma nota baixo no quinto ou décimo minuto de vida. Evidenciasse nas pesquisas existentes, que os recém-nascidos que recebem notas do Apagar abaixo de sete no quinto minuto, apresentem complicações com possível comprometimento no desenvolvimento neuropsicomotor, por isso a importância de analisar as notas de Apgar (Ermel \& Grave, 2011).

Dentro das notas do Apgar verificadas na pesquisa atual ( $45 \%$ da amostra), todas as crianças receberam nota maior que 7 no quinto minuto, o que não caracterizaria necessidade de intervenção precoce ou que desenvolveriam comprometimento no desenvolvimento neuropsicomotor. Apesar das CRIANES também terem recebido nota superior a 7 no quinto minuto, outras intercorrências durante e após o parto, como anóxia, convulsão e icterícia, podem ter sido fatores primordiais para que esses bebês se tornassem crianças com necessidades especiais de saúde.

A partir da leitura, análise e a organização das informações obtidas, por meio das entrevistas realizadas com as cuidadoras, elaborou-se três categorias temáticas que destacaram os conteúdos principais das respostas obtidas. Essas categorias serão discutidas adiante e foram nomeadas 1) O impacto da maternidade no cotidiano dos cuidadores; 2) Relação bem-estar e suporte social; 3) O bem-estar influenciado pela condição de saúde da criança.

\section{Discussão}

a importância de se estudar o cuidador, dentro das mais variadas populações, está no fato de que sobre eles recai uma sobrecarga, decorrente, entre outros fatores, de uma pesada rotina de cuidados despendidas que afeta sua saúde física e mental. Conforme Sales (2003), há dois tipos de sobrecarga a que são submetidos os cuidadores: a objetiva, que inclui o tempo oferecido às necessidades concretas do cotidiano do paciente, como a supervisão das necessidades diárias e financeiras; e a sobrecarga subjetiva, definida como uma experiência que gera um grande estresse de caráter emocional, podendo ser constituída pelo sentimento de culpa, vergonha, tristeza, baixa autoestima e preocupação excessiva com o familiar doente.

\section{O impacto da maternidade no cotidiano dos cuidadores}

Voltado para uma sobrecarga objetiva, todas as cuidadoras relataram mudanças significativas no cotidiano após a maternidade, principalmente relacionadas ao trabalho, estudos, atividades de lazer, participação social, tempo para si mesmas, descanso e rotina de cuidado com a criança. No que se diz respeito ao lazer e participação social, Pontes (2008) traz em seu estudo que a maior parte das mães participantes vivenciavam momentos de lazer e descontração, porém essas vivências eram pouco frequentes, sobretudo, pelas limitações 
TABELA 2. DADOS DAS CRIANÇAS SEGUNDO GESTAÇÃO, NASCIMENTO E DESENVOLVIMENTO.

\begin{tabular}{|c|c|c|c|}
\hline VARIÁVEL & $\begin{array}{l}\text { DADOS GERAIS DAS } \\
\text { CRIANÇAS }(n=20) \text { em \% }\end{array}$ & CRIANES (n=10) & $\begin{array}{l}\text { CRIANÇAS TÍPICAS } \\
(\mathrm{n}=10)\end{array}$ \\
\hline \multicolumn{4}{|l|}{ SEXO } \\
\hline Feminino & 65 & 5 & 8 \\
\hline Masculino & 35 & 5 & 2 \\
\hline \multicolumn{4}{|l|}{ FAIXA ETARIA } \\
\hline 0 a 2 anos & 30 & 3 & 3 \\
\hline 2 a 4 anos & 30 & 3 & 3 \\
\hline 4 a 7 anos & 30 & 3 & 3 \\
\hline 7 a 12 anos & 10 & 1 & 1 \\
\hline \multicolumn{4}{|l|}{$\begin{array}{l}\text { INTERCORRÊNCIAS NA } \\
\text { GESTAÇÃO }\end{array}$} \\
\hline Doença infectocontagiosa & 10 & 2 & 0 \\
\hline Acidentes & 10 & 2 & 0 \\
\hline Não & 80 & 6 & 10 \\
\hline \multicolumn{4}{|l|}{ MEDICAÇÃO NA GESTAÇÃO } \\
\hline Sim & 10 & 2 & 0 \\
\hline Não & 90 & 8 & 10 \\
\hline \multicolumn{4}{|l|}{ SITUAÇÃO DO NASCIMENTO } \\
\hline Hospital & 95 & 10 & 9 \\
\hline Casa & 5 & 0 & 1 \\
\hline \multicolumn{4}{|l|}{ TIPO DE PARTO } \\
\hline Cesariana & 55 & 7 & 4 \\
\hline Natural & 45 & 3 & 6 \\
\hline \multicolumn{4}{|l|}{ IDADE GESTACIONAL } \\
\hline Pré-termo extremo & 10 & 1 & 1 \\
\hline Pré-termo & 15 & 3 & 0 \\
\hline A termo & 75 & 6 & 9 \\
\hline \multicolumn{4}{|l|}{ APGAR 5' } \\
\hline$>7$ & 45 & 5 & 4 \\
\hline Não consta & 55 & 5 & 6 \\
\hline \multicolumn{4}{|l|}{ PESO AO NASCIMENTO } \\
\hline Muito baixo peso $(<1500 \mathrm{~g})$ & 10 & 1 & 1 \\
\hline Baixo peso (1500 a 2500g) & 15 & 2 & 1 \\
\hline Peso normal (2500 a 3800g) & 55 & 5 & 6 \\
\hline Sobre peso $(>3800 \mathrm{~g})$ & 10 & 0 & 2 \\
\hline \multicolumn{4}{|l|}{ DIAS DE INTERNAÇÃO } \\
\hline 0 a 10 dias & 70 & 6 & 8 \\
\hline 11 a 30 dias & 10 & 1 & 1 \\
\hline$>60$ dias & 20 & 3 & 1 \\
\hline \multicolumn{4}{|c|}{ INTERCORRÊNCIAS NO PARTO } \\
\hline Não & 55 & 2 & 9 \\
\hline Sim & 45 & 8 & 1 \\
\hline
\end{tabular}

Fonte: Dados da pesquisa. 
da condição de saúde da criança e sua intensa rotina de cuidados. Este fato ficou evidenciado na pesquisa atual pelas respostas sobre a participação em eventos sociais e de lazer, em que a maioria das cuidadoras de CRIANES não participava devido à condição de saúde da criança, que as impedia de frequentar certos locais ou por não terem um cuidador secundário com quem pudessem deixar a criança. Essa questão pode ser ilustrada pelas falas de cuidadores participantes:

"Assim, eu não participo mais dessas coisas porque é mais difícil né. Acho que mudou tudo, praticamente tudo, porque na verdade eu vivo só para ele mesmo, eu não saio de casa (...) antigamente eu ia bastante (eventos sociais), agora não vou mais, é muito difícil sair por causa da cadeira de rodas dele." (C1)

"Até no fim de semana o tempo é para os filhos. Dieta, medicação, não saio de casa para nada." (C6)

"Não (participo) ...quando a D. recebeu o diagnóstico da síndrome, me afastei muito das pessoas e de tudo. Me sentia melhor no meio de outras mães com criança especial, identificava mais (...). Então dedico mais meu tempo a D. e irmão mesmo." $\left(C_{7}\right)$

Silveira e Neves (2012) alegam que o cuidado à CRIANES acabara sendo desenvolvido pelos familiares mais próximos e restrito aos pais e/ou vós, exigindo da família tempo integral, o que dificultava a vida social destes cuidadores. As falas acima dos participantes vêm de encontro ao que a literatura de Silveira e Neves (2012) apresentaram em seu estudo.

Outro impacto no bem-estar que pôde ser verificado em relação a não participação foi em decorrência da falta de tempo por causa da rotina de cuidado da casa, de outros filhos e/ou trabalho, assim como outras cuidadoras de crianças típicas, que participavam pouco devido aos mesmos motivos mencionados.

"Não, mas não é devido somente a minha neta, é mais devido a outras tarefas de casa; mas a V. não é um impedimento para eu fazer as coisas." (C8)
"Antes eu saia para festa show, barzinho, trabalho, fazia academia, cuidava de mim... Agora mais nada, nem penso em mim nem me importo nisso." (C4)

"Raramente, mudou minha rotina de lazer, saídas à noite, encontro com amigos e barzinhos." (T15)

Sobre isso, Ribas et al (2006) traz que, com frequência pessoas que vivenciam estresse e sobrecarga reduzem horas de sono, sentem-se aprisionadas pela rotina, sem tempo para descanso e lazer, e relatam que o tempo para estar com filhos, amigos e familiares é insuficiente.

Em contrapartida, na pesquisa atual foi verificado pela fala das participantes cuidadoras de crianças com desenvolvimento típico, que a maioria tinha a possibilidade de participar de eventos sociais e de lazer. Tais menções são ilustradas nas falas:

"Sim, mas não levo minha filha em alguns lugares por não ser apropriados para criança, mas em outras ocasiões é bem tranquilo." (T16)

"Maior parte das vezes, após um ano (do nascimento)" (T19)

Quando questionadas sobre tempo para realizar as atividades de vida diária e de cuidado, metade das cuidadoras de crianças com desenvolvimento típico, tinham tempo para realizar o que gostariam além das obrigações com a criança, principalmente aos finais de semana:

"Sim, consegui encaixar E. em nossa rotina então não mudou muita coisa" (T14)

"Em partes sim, o que me toma mais tempo no momento é a faculdade, fora ela os demais assuntos fluem relativamente bem." (T18)

"Eu divido o fim de semana com o pai e família paterna (...) então dependendo do dia consigo um pouco mais de tempo livre enquanto ela está com eles." (T11)

Os dados da pesquisa atual mostram que algumas mães de crianças com desenvolvimento típico conseguiram se adaptar à rotina nova, e dedicaram algum tempo ao 
descanso e lazer, mesmo com a sobrecarga da rotina de cuidado e outras não possuíam esse tempo. As cuidadoras de CRIANES, relataram não possuir tempo suficientemente bom para realizar as tarefas diárias, tampouco para lazer, pois o tempo delas era dedicado exclusivamente à criança, inclusive aos finais de semana.

"Não, meu tempo é totalmente para ela, para cuidar dela, ela precisa de atenção todo o tempo. Antes eu gostava muito de me cuidar com manicure, cabelo, sobrancelha, nunca mais." (C5)

"Com certeza não (tenho tempo suficiente). Ele tem que estar junto comigo 24 horas por dia, para ele dormir, se eu lavar louça ele tem que ficar do meu lado, senão chora, entra em prantos e gritos." (C4)

"Não, médico demais, escolinha, problema respiratório. O tempo que tenho descanso ou arrumo a casa" $\left(C_{3}\right)$

Corroborando com esses dados, o estudo de Pinho, Da Silva, Souza e Correa (2019) sobre cuidadores de pessoas em cuidados paliativos oncológicos, também alegaram que em diversas situações, o cuidador não cumpria esse fazer apenas para com o familiar. Em casa, tinha afazeres que envolviam outras ocupações de cuidar, como cuidar dos filhos, do marido, da organização da casa ou trabalho, assim, a responsabilidade de ser um cuidador tornava-se ainda maior.

Dentre as mudanças ocorridas decorrentes da maternidade no quesito ocupações e tempo para si mesmas, dez cuidadoras de CRIANES e seis de crianças típicas tiveram que desistir do emprego, oportunidades melhores e/ou estudos para ter tempo de cuidar da criança. Esta questão foi recorrentemente trazida pelas entrevistas como algo que faz muita falta na vida e as mães/cuidadoras mencionaram ainda que gostariam de mudar se fosse possível, tanto na questão financeira quanto na independência e realização pessoal. Algumas famílias já possuem condição precária, algumas vezes dependendo apenas do Benefício de Prestação Continuada (BPC), o que causa uma outra preocupação e um impeditivo em certas situações. Esse BPC é um benefício/renda mínima de assistência social no Brasil, previsto na Lei Orgânica da Assistência Social (LOAS) número 8.742, de 7 de dezembro de 1993, desde então oferecido a idosos com mais de 65 anos de idade e pessoas com deficiência que não possuem capacidades para uma vida independente e para inserção/reinserção social e no mercado de trabalho. Ou ainda para aqueles que não possam ser mantidos financeiramente por seus familiares (Brasil, 1993).

Em congruência com este fato, a investigação de Pontes (2008), também constatou a modificação da relação com o filho, no sentido de um aumento de dedicação e cuidado, levando às cuidadoras, sem exceção, a uma reorganização da vida profissional ou ao seu completo abandono. Em relação a vida profissional das mulheres, é importante ressaltar sobre a desigualdade de gênero no mercado profissional e a divisão do trabalho tradicional, que de modo geral reconhece que as atividades produtivas (trabalho remunerado) e as funções com maior valor social, fazem parte de um espaço predominantemente masculino, enquanto as atividades reprodutivas (esfera familiar e doméstica), são prevalentemente femininas (GUIGINSKI; WAJNMAN, 2019). Portanto, a desvalorização cultural e institucional das atividades tradicionalmente associados à mulher - serviços de cuidado e domésticos - traz pouca motivação para que os homens se dediquem a estas atividades, fazendo com que a dimensão dos cuidados, em particular com os filhos, permaneça substancialmente como atribuição feminina (FOLBRE, 2012).

Esses dados foram mencionados nas falas:

“(...) eu amo trabalhar, fico com vontade de trabalhar de novo, sou cozinheira. A minha vontade é de poder trabalhar de novo mesmo de cozinheira, mas eu não posso (...) acho que distrai a cabeça e ajuda a renda, agora só vivo com o BPC é muito difícil. Mas ele está em primeiro lugar em tudo e por enquanto não dá." (C7)

"Sim, tive que parar a minha vida, porque eu saí do trabalho para cuidar da minha neta pra minha filha (mãe dela) poder trabalhar (...) e me angustia porque eu sou mãe, mas não sou ao mesmo tempo, porque eu sou avó. (...) como eu te explico... é como você escrever um livro e não assinar, não estar seu nome, você não ser a autora." (C8)

"(desisti de) Oportunidades de trabalho e um intercambio" (T18) 
"Parei de trabalhar... Mudou muito, antes eu trabalhava de segunda a sábado de diarista, saia mais... Agora é viver pra ela. Eu costumava sair mais e cuidar mais de mim, mas é no momento o dinheiro do benefício (BPC) que tem éo que dá pra pagar as coisas dela e só" $\left(C_{5}\right)$

\section{"Desisti de empregos e cursos" (T13)}

Como visto no estudo de Da Silva e Barros (2019), o afastamento do cuidador responsável pela criança de seu papel ocupacional de trabalhador, gera sobrecarga financeira da família, pois a renda sofre um declínio e se faz necessário o uso de reservas financeiras. Traub e Mengarda (2016) enfatizam ainda que as famílias mais atingidas por essa sobrecarga financeira são aquelas que já possuíam salários baixos.

"Toda minha rotina mudou. Antes era só eu, trabalhava pra mim, tinha tempo livre pra fazer o que eu quisesse, mesmo trabalhando em shopping, hoje eu trabalho pra sustentar principalmente ela. Se pudesse eu trabalharia pelo menos em um emprego que fosse de segunda a sexta, assim teria mais tempo livre para mim e pra L." (T11)

"Não tenho muitas escolhas, trabalho pela manhã e cuido da minha filha o restante do dia. Gostaria de cuidar mais do corpo se tivesse tempo." (T19)

Este ponto convergente entre os dois grupos de cuidadores, ilustrou o impacto da maternidade nas ocupações e escolhas profissionais dessas mulheres, que estavam majoritariamente em idade produtiva. $\mathrm{O}$ estudo de Beltrame e Donelli (2012), apontou que a tentativa de conciliar a maternidade e a carreira podia provocar um conflito e nesse sentido, as mulheres que optavam ou se tornavam mães sofriam estigma social e sobrecarga emocional, além de terem uma tendência a postergar o retorno ao trabalho. Segundo Guiginski e Wajnman (2019), a persistência cultural das desigualdades de gênero tanto no mercado de trabalho quanto na esfera privada, resulta em uma sobrecarga de responsabilidade e trabalho para as mulheres brasileiras, dificultando a conciliação das responsabilidades familiares e profissionais e assim, afetando o seu bem-estar.

\section{Relação bem-estar e suporte social}

O apoio social é fundamental ao longo do desenvolvimento humano, principalmente em períodos de transições e mudanças, quando são exigidas adaptações à nova vida e o indivíduo passa por situações de estresse; o nascimento de um filho, por exemplo, é uma dessas situações (Rapoport \& Piccinini, 2006).

Os dados do presente estudo mostraram que a relação entre a sobrecarga sentida e o apoio social recebido, principalmente dos cônjuges e/ou familiares, é inversa, ou seja, quanto maior o apoio recebido, menor a sobrecarga sentida. A maioria de cuidadoras de crianças típicas consideraram suficiente o apoio recebido do companheiro e/ou familiar próximo, e foram as mesmas que se sentiam as vezes ou nunca sobrecarregadas por serem cuidadoras. Tal relação está ilustrada nas falas seguintes:

"Sim, total apoio (suficiente)" e "Não sinto (sobrecarga), é um prazer cuidar dele" (T12)

"Não me sinto sobrecarregada pois tenho pessoas que me ajudam muito" (T14).

Segundo Brito e Koller (1999), pessoas que têm boas redes de apoio social e afetivo são mais competentes para oferecer apoio e estabelecer relações próximas e significativas, integrando a rede de apoio de outras pessoas, e tendem a ter capacidade aumentada para enfrentar eventos estressantes da vida.

Entretanto, o inverso também foi observado na pesquisa atual. As cuidadoras de crianças típicas que não recebiam apoio suficiente, sentiam sobrecarga em seu papel de cuidador. O apoio da família ao cuidador, quando acontecia, ocorria de formas diferentes e com algumas condições, no sentido de agilizar o cuidado ou de permitir que o familiar cuidador pudesse suprir suas próprias necessidades, enquanto designava temporariamente sua função de cuidar. Entretanto, pode ocorrer a fragilização do cuidador principal quando não acontece ou não existe este apoio (Lima, de Paulo \& Higarashi, 2013). Isso pôde ser evidenciado através de seguintes falas: 
"Não tenho (apoio suficiente)" e "Bastante sobrecarga, pois mesmo tendo ajuda do pai e da família, ela passa a maior parte do tempo comigo. Ouço muitas coisas ruins das pessoas (até da minha família), cobrança desnecessária, desvalorização, e isso só me afeta negativamente."(T11)

As cuidadoras de CRIANES que relataram não receber apoio suficiente ou nenhum apoio, trouxeram em seus relatos maiores níveis de sobrecarga, emocional e física, comparado aquelas que recebiam apoio suficiente dos companheiros e/ou familiares.

"(Suficiente)Não, tenho apoio da minha mãe apenas. Pai dele não, nem família, não convive, não ajuda e não visita." e "Uns 9o\% (sobrecarregada), é muito desgastante. Até por ele não aceitar outras pessoas pra olhar ele, mesmo que minha mãe esteja ali, ele não fica com ninguém então me sobrecarrega bastante". (C4)

"Nenhum apoio, em casa tem até mas podia ser mais, porque sou eu pra tudo, então precisava de muito mais." e "Extremamente sobrecarregada, o cansaço, correr, vigiar, é muito exaustivo" (C6)

As cuidadoras que não recebiam nenhum apoio, foram as mesmas mulheres que se encontravam solteiras no momento e que não possuíam ajuda do pai e ou/ família paterna, além de não terem tido apoio social dentro da própria família e rede de amigos. Estas relataram maiores sobrecargas, objetivas e principalmente subjetivas e emocionais. Essa sobrecarga subjetiva maior pode ser explicada segundo De Araujo, Reichert, Oliveira e Collet (2011), que afirmam que apoio emocional, que consiste em afeto, em estima e em consideração à família, em acompanhamento e em escuta, ajuda os familiares a se sentirem mais seguros, confiantes e recompensados pelo cuidado prestado à criança. A fala a seguir exemplifica a falta de apoio emocional:

"Não, é mais dos meus filhos de 9 e 20 anos, mas não é suficiente (o apoio). Exemplo, o pouquinho que você está mal e fica no colo da sua mãe 15 minutos já ajuda, eu não tenho isso nunca. Tem coisa que não posso desabafar com meus filhos, não tenho ninguém para poder dividir os problemas e as coisas" $e$ "Não tenho família aqui perto, que posso sair, conversar, eles na Bahia e eu aqui. Amigos também não tenho, só para pedir coisas, mas para ajudar e dar apoio nenhum. Então somos eu e meus 3 filhos apenas." $\left(C_{5}\right)$

A falta de apoio emocional ocasiona maior sobrecarga sobre os cuidadores, visto que é muito importante que eles tenham um espaço para trabalhar e verbalizar as emoções e sentimentos, ajudando-os a compreender as reações comuns nessas situações de estresse (Bifulco \& Caponero, 2016).

Em compensação, algumas dessas mães solteiras, relataram ter bastante contato e convivência com mães de outros CRIANES, e que isso às auxiliavam em certos processos de preocupação, estresse e era uma forma de lazer em certos momentos. Este auxílio foi muito importante, visto que para Rapoport e Piccinini (2006), quando o apoio conjugal está ausente, a rede de apoio social de amigos e parentes é o principal sistema de apoio.

"O grupo "mães de anjos especiais" que temos no Whatsapp...fazemos reuniões as vezes de sábado, é muito divertido e gostoso. Falamos de coisas sérias e também diverte." (C6)

As outras cuidadoras que consideraram receber apoio suficiente, relataram uma sobrecarga diária menor, e especificaram que se sentiam mais sobrecarregadas devido à correria de dias específicos, afazeres domésticos, ou problemas externos pontuais.

"(Me sinto) muito cansada por causa de várias atividades no dia, terapias fora de casa." E Muito apoio do meu marido e filhos. É muito cansativo todo dia e ele chega do trabalho e faz tudo que precisa com as crianças e com a casa, desde sempre. Quando precisa tirar leite para a D. internada, ele tirava o leite pra mim de madrugada mesmo eu dormindo na metade de tão exausta." $\left(C_{7}\right)$

"Sim (tenho apoio), agora está dando certo, tive que resolver umas questões, mas agora está tudo certo" e "Tem dia que sim (sobrecarregada), porque são gêmeos muito diferentes e cada um exige de um jeito" $\left(C_{3}\right)$

"Do esposo e filhos sim (apoio suficiente). Do resto da família não tem muito contato, cada um no seu canto, somos amigos e só. Eu não

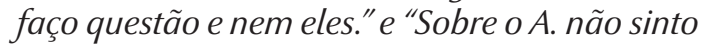


(sobrecarga), mas quando tenho que entrar em briga de esposo e filhos, me desestabiliza um tempo" (C19)

Nesse sentido, De Araujo, Reichert, Oliveira e Collet (2009) enfatizam que a própria família é a principal rede de apoio e que não é a quantidade de pessoas que faz essa rede fortalecida, mas a qualidade das relações. Assim, pôde-se observar que as cuidadoras da atual pesquisa que possuíam apoio suficiente, mencionaram que esse apoio advinha de uma ou duas pessoas da família, e a qualidade era tão boa que consideravam suficiente para elas, não necessitando de outros apoios para diminuição da sobrecarga.

\section{O bem-estar influenciado pela condição de saúde da criança}

Sabe-se que, desde muito tempo, o papel de cuidador principal é destinado à figura materna, tratando-se de uma ideia difundida a partir do século XVIII, onde a mãe se tornara cuidadora do filho numa ligação intrínseca com aquele a quem dispensava os cuidados (Badinter, 1985). Frisando esta questão cultural de gênero, sobre a concepção de maternidade, diversos estudos têm afirmado que, embora todos os membros da família sofram e sejam afetados pela condição crônica da criança, é a figura materna que acaba por sofrer mais intensamente (Pontes, 2008)

Segundo Delalibera, Presa, Barbosa e Leal (2015), as demandas exigidas de cuidado de um ente familiar, muitas vezes doente, têm prioridade sobre as demais atividades, ocupações, relações sociais e lazer do cuidador. O cuidador principal, na maioria das vezes a mãe, quase não tem tempo para si, para atividades sociais, muitas vezes precisa reduzir a carga horária de trabaIho ou abandona-lo para cuidar do seu familiar; além de que com o excesso de tarefas de cuidado a serem desempenhadas, o cuidador fica sobrecarregado e como consequência é muito provável que a sua saúde também fique prejudicada (Delalibera, Presa, Barbosa \& Leal 2015).

Este fato pôde ser evidenciado através dos relatos das cuidadoras de CRIANES, sobre as restrições em suas rotinas devido à condição de saúde das crianças e suas demandas diárias de cuidado. Exemplificado pelas falas:
"Tudo, não saio para lugar nenhum, se ele não se sente bem em certos lugares, como mercado, ele chora, então me restringi de tudo. Só posso estar em lugares que ele fique bem." (C4)

"Sim restringe para tudo, mas é uma restrição gostosa, melhor estar assim do que não ter, pois na mesma hora que está aqui pode não estar mais. Não aproveito outras coisas, mas aproveito os filhos ao máximo. Eu e os dois irmãos brigam pela atenção da J."(C6)

“(..) sim, porque eu preservo muito ele. Ele tem resistência muito baixa então não exponho muito ele a lugares que possa trazer alguma complicação." (C2O)

Sobre as perguntas a respeito dos sentimentos em relação ao futuro da criança e a convivência com outras pessoas e familiares, todas as mães relataram sentimentos de medo e preocupação a respeito do futuro da criança. As mães, principalmente de crianças com síndromes ou necessidades mais incapacitantes relataram também sentimentos negativos derivados de olhares diferentes e preconceituosos vindo de terceiros e de dentro da própria família, como relatado a seguir:

"Enquanto eu viver eu cuido dele. É cansativo é, não vou mentir. Mas nós mães temos força. $\dot{E}$ filho da gente, posso estar cansada, estressada, mas vou fazer o infinitivo por ele. Tenho muito medo das outras pessoas, dos outros não cuidarem dele direito igual a mim. Hoje em dia tem muito preconceito, já sofri muito preconceito na vida por sernegra, e ainda quando tem filho com deficiência, é mais ainda. Já vivi na pele de pessoas xingar a mim exingar ele, então esse é meu medo, de fazerem maldade, judiar..."(...) as pessoas tem muito preconceito, étabu até mesmo da família. Então as vezes evitamos familiares, discussões, mágoas, então nos afastamos."

"Vou ser capaz de cuidar dele para o resto da vida. Sinto bastante medo, do convívio social e pelo preconceito. Penso no futuro dele na escolinha, como vai ser, se ele vai ser aceito..." (C4).

"Sinto muito medo, peço a Deus para que tudo dê certo, até prefiro que leve ela antes de mim porque não vaiter quem cuidar, gosto nem de pensar 
nisso. Filho sem necessidade já á dependente, na condição dela então, ela é total dependente de mim."(C6)

"Não tenho muito contato com a família porque não entende que eles precisam de cuidado especial, nem olham a deficiência dela "bem". Agente vive nos 5." $\left(C_{7}\right)$

Com relação à essas percepções de olhares de terceiros, corroborando com o que Green (2007) encontrou, muitas vezes o estresse e sofrimento emocional decorre mais da discriminação e preconceito de outras pessoas para com a criança, do que necessariamente da rotina de cuidados da criança; podendo resultar em autoestima e confiança afetados pelo estigma social.

Ainda, Pontes (2008) traz em seu estudo que o temor pela vida do filho, a incerteza quanto ao seu futuro, e a constatação de que sua dependência e a falta de autonomia são aspectos, diretamente relacionados à vida da criança, que se refletem de maneira negativa nessa experiência de maternidade.

A maior parte das entrevistadas, quando questionadas sobre o cansaço/exaustão psicológica e física relacionados ao papel de cuidador, relataram sofrer muito mais cansaço e sobrecarga emocional do que física. Tem-se as seguintes falas:

"É muito cansativo, na cabeça é mais do que no corpo. Éa cabeça que comanda tudo, se não tiver bem da cabeça, o corpo não vai." (C $\left.C_{5}\right)$

"Muito cansada, extremamente, mãe é o extremo da felicidade, da raiva, do cansaço. Muito sentimento para uma cabeça só." e "muito mais emocional. Físico dá para deitar e descansar, o emocional parece que não passa" $\left(C_{3}\right)$

"Com certeza, por enquanto ainda é mais emocional, mas o físico também é bem desgastante." (C4)

"Mais emocional, quando ele nasceu chorei muito, agora é um milagre na minha vida. (Cansaço) Físico não sinto." (Cg)

Corroborando com os achados do presente estudo, Mendes, Figueiredo, Santos, Fernandes \& Fonseca (2019) em sua investigação sobre sobrecarga de cuidadores informais de idosos, apresentou que os cuidadores com maior sobrecarga são aqueles que têm manifestado uma pior saúde subjetiva, ou seja, no âmbito emocional e psicológico.

Sobre as implicações disto, Bastos (2008) traz que a sobrecarga subjetiva quando tão intensa e árdua, pode alterar a qualidade de vida de quem cuida e não apenas de quem é cuidado, pois pode acarretar alterações emocionais, como depressão, ansiedade, e problemas físicos.

Apesar de toda a sobrecarga e fatores negativos presentes no cotidiano dessas cuidadoras, ao serem indagadas sobre os sentimentos relacionados ao papel de cuidadora, todas, sem exceção, relataram apenas sentimentos positivos de amor, dedicação, orgulho, alegria, aprendizado e de força. Explicitados abaixo:

"(Sentimentos) De muito amor e gratidão a Deus por ter me emprestado um ser tão importante e especial, que me ensina a ter força e determinação para vencer qualquer obstáculo. A cada dia vejo o quanto a V. é forte e esperta, uma vitoriosa. Sou muito feliz por acordar todos os dias e ver o sorriso lindo que ela me presenteia, com sua "sapequisse" me chamando a atenção para algo novo que ela está fazendo. As gargalhadas de alegria quando brinco om ela, e um amor incondicional que nada no mundo vai apagar. Sou feliz porque sei que ela é feliz, ela me mostra isso a cada instante de nossas vidas." (C2)

"Pra conseguir ser mãe, você precisa de amor. Senão você não cuida, não dá conta, então o que eu sinto é puramente muito amor. Sinto que dou 
meu melhor, faço tudo que posso, as vezes a gente se sente culpada por uma falta de paciência, por estresse, mas acho que me saio bem como mãe e cuidadora." (C4)

"Sentimento bom, muito feliz, independentemente de qualquer coisa, da chuva e do sol. Porque acho que se eu não tivesse isso tudo, eu estou sendo bem preparada por Deus, a gente reclama, mas passa porque não vive sem." $\left(C_{5}\right)$

"Sentimento de muito amor, carinho e preocupação. Às vezes você pode estar mal, eles mostram um lado bom, eu aprendo mais com ele do que eles comigo. Quanto é bom ver o aprendizado deles, eles são muito bons, não veem maldade em ninguém e estão sempre alegres, para cima." $\left(C_{7}\right)$

\section{"Cuidar de uma criança é uma coisa que te acorda para a vida, você vê que você tem uma força que você não sabe que tem. Eu estou muito cansada, mas eu faço coisas que... eu não sei como con- sigo fazer tudo isso de novo, porque meu rendi- mento é menor devido a minha idade, édiferente quando fui mãe aos zo anos. Mas é satisfató- rio eu me sinto muito feliz de cuidar das minhas duas netas, ver elas aprendendo, o carinho que elas têm comigo." (C8)}

Segundo Folbre (2012), as motivações que fazem com que as mulheres tomem para si as responsabilidades pelos cuidados, têm origem nas normas sociais e nos valores morais, mesmo que fatores biológicos impliquem diferenças entre homens e mulheres. A maior predisposição das mulheres para o cuidado com os filhos é muito mais influenciada pelas normas e imposições socioculturais e amplificada pelas instituições sociais do que estritamente devido a fatores biológicos. Entretanto, independentemente da origem das motivações e preferências, a atribuição do papel de cuidadora para as mulheres resulta em riscos econômicos e desvantagens na esfera produtiva, podendo ou não aumentar sua satisfação na esfera familiar (FOLBRE, 2012).

Segundo Mafra (2011), o ato de cuidar, em sua essência, está contido em uma relação de obrigação e de responsabilidade para com a pessoa dependente, sendo uma norma social influenciada por eventos socioculturais. Assim, o sentimento de cumprimento de normas sociais e a necessidade de autopreservação, na busca de evitar sentimento de culpa e julgamentos externos, são alguns fatores que levam a uma pessoa a cuidar de alguém (MAFRA, 2011). Além disso, realizando a tarefa do cuidar, o cuidador passaria a sentir-se bem, receberia reconhecimento social e uma melhora no senso de realização pessoal, por conseguir fazer aquilo que se espera dele, porém, quando essa tarefa perdura por muito tempo ou exige muito, o cuidador passa a se sentir sobrecarregado e por vezes, passa a não mais perceber os aspectos positivos nesta relação, por sentir que "recebe" pouco comparado ao que se "doa". (MAFRA, 2011).

Por outro lado, Aitken (2014) afirma que cuidar de quem se ama pode ser, ao mesmo tempo, uma das experiências mais dolorosas e uma oportunidade de se descobrir habilidades antes desconhecidas, como pontos fortes e fracos, e que ao mesmo tempo sentirá orgulho e bemestar por estar fazendo o que realmente deve fazer.

\section{Conclusão}

O presente estudo possibilitou investigar e compreender as experiências vividas pelas cuidadoras participantes. A maioria dessas mães e avós, principalmente cuidadoras de CRIANES, ao se dedicarem integralmente à essas crianças, abdicaram de vivencias pessoais em prol dos filhos/netos, ocasionando em perda de papéis, frustração profissional e financeira, restrição social e de lazer, mudanças em relações e abandono do olhar e cuidado consigo mesmas, mas também descobriram sentimentos positivos em relação aos cuidados. A partir dos resultados do estudo, infere-se que as alterações no cotidiano materno, nas possibilidades de escolhas na vida diária e do suporte social recebido ou não, irão interferir no bem-estar tanto de cuidadoras de crianças típicas quanto de crianças com necessidades especiais, sendo que estas sofrem maior impacto em seu bem-estar.

Em vista dos resultados, compreende-se ainda que os cuidadores também precisam de cuidado e geralmente recebem pouco, por isso, é importante que os profissionais da saúde, proponham intervenções que objetivem minimizar o sofrimento, a sobrecarga e colaborar para uma melhora no bem-estar e na qualidade de vida desses cuidadores de CRIANES. Essas intervenções não precisam se restringir necessariamente ao atendimento individual do cuidador, é viável também, realizar 
em ambientes hospitalares, ambulatórios ou casas de apoio, os grupos terapêuticos, oficinas e terapia comunitária, por exemplo. Proporcionando assim, uma assistência mais integral à saúde, uma prática centrada nas demandas do cliente e de sua família. Uma das possíveis limitações desse estudo foi a falta de investigação mais detalhada sobre como redes de apoio poderiam contribuir com ou assistir melhor os cuidadores participantes dessa pesquisa. Outra possível limitação desse estudo está relacionada ao número de participantes que, apesar das riquezas de informações fornecidas por eles, foi considerado pequeno. Logo, novas pesquisas podem ser realizadas com grupos maiores de cuidadores.

Visto que há uma escassez de dados e pesquisas sobre o tema específico do bem-estar de cuidadores de crianças com necessidades especiais, e de como se dá a sobrecarga e o impacto do cuidado dessas crianças nas diferentes áreas da vida desses cuidadores, principalmente no campo da Terapia Ocupacional, este estudo foi importante para ampliar os conhecimentos sobre o cuidador e suas dimensões, podendo contribuir com os demais profissionais da área da saúde para um olhar mais atento à esta população.

\section{RefERENCIAS BibLIOGRÁfiCAS}

Aitken, E. V. P. (2014). Um dia de cada vez. São Paulo: Cultura Cristã.

Badinter, E. (1985). Um amor conquistado: o mito do amor eterno. Rio de Janeiro: Nova Fronteira, p. 370.

Bastos, C. P. (2008). Qualidade de vida relacionada à saúde de cuidadores de crianças e adolescentes com doença falciforme (Tese de mestrado). Universidade Federal de Uberlândia, Uberlândia, Minas Gerais.

BRASIL, Lei n ${ }^{\circ} 8.742$, de 7 de dezembro de 1993, Art. 20. Casa Civil da Presidência da República.

Bee, H. \& Boyd, D. (2011). A criança em desenvolvimento; tradução Maria Adriana Verissimo Veronese. $12^{\mathrm{a}}$ edição. Porto alegre: Artmed.

Beltrame, G. R, \& Donelli, T. M. S. (2012). Maternidade e carreira: desafios frente à conciliação de papéis. Aletheia, v38, 206-217.

Bifulco, V. A. \& Caponero, R. (2016). Cuidados Paliativos: conversas sobre a vida e a morte na saúde. Barueri: Manole.

Brito, R., \& Koller, S. H. (1999). Desenvolvimento humano e redes de apoio social e afetivo. In A. M. Carvalho (Ed.), O mundo social da criança: natureza e cultura em ação. São Paulo: Casa do Psicólogo.

Comaru N.R.C. \& Monteiro A.R. (2008). O cuidado domiciliar à criança em quimioterapia na perspectiva do cuidador familiar. Rev Gaúcha Enferm, 29(3), 423-30.
Cochran, M. \& Niego, S. (1995). Parenting and social networks. In M.H Bornstein (Ed.), Handbook of parenting: Status and social conditions of parenting. NY: Lawrence Erlbaum Associates.

Da Silva, I. C. B. \& de Barros, M. M. M. (2019). Las experiencias de los cuidadores familiares de niños y adolescentes con câncer. Revista Chilena de Terapia Ocupacional, 19(1), 35-48.

De Araujo, Y. B., Reichert, A. P., Oliveria, B. E. R., Collet, N. (2009). Rede e apoio social de famílias de crianças com doença crônica: revisão integrativa. 10(4).

Delalibera, M., Presa, J., Barbosa, A. \& Leal, I. (2015). Sobrecarga no cuidar e suas repercussões nos cuidadores de pacientes em fim de vida: revisão sistemática da literatura. Ciênc. Saúde coletiva, 20(9), 2731-2747.

Ermel, a. C., \& Grave, m. T. Q. (2011). O índice de apgar em bebês recém-nascidos em um hospital de pequeno porte de um município do vale do paranhana. Revista destaques acadêmicos, 3(3).

Folbre, N. (2012). Should women care less? Intrinsic motivation and gender inequality. British Journal of Industrial Relations, v. 50, n. 4, 597-619.

Green, S. E. (2007). "We're tired, not sad": benefits and burdens of mothering a child with disability. Social Science \& Medicine, New York, v64, 150-163.

Goldbeck, L. (2006). The impact of newly diagnosed chronic paediatric conditions on parental quality of life. Quality of Life Research, 15, 1121-1131.

Gil, A. C. (2010). Como elaborar projetos de pesquisa. $5^{\mathrm{a}}$ ed. São Paulo: Atlas. Guiginski, J., Wajnman, S.. (2019). A penalidade pela maternidade: participação e qualidade da inserção no mercado de trabalho das mulheres com filhos. Rev Bras Est Pop, 36, 1-26.

Lima M. F., de Paulo L. F. \& Higarashi, I. H. (2013). Crianças dependentes de tecnologia: o significado do cuidado domiciliar - estudo descritivo. Online Braz J Nurs, 14 (2), 178-89.

Mendes P. N., Figueiredo M. L. F., Santos A. M. R., Fernandes M. A. \& Fonseca R. S. B. (2019). Sobrecargas física, emocional e social dos cuidadores informais de idosos. Acta Paul. Enferm. 32(1), 87-9.

Mafra, S. C. T. (2011). A tarefa do cuidar e as expectativas sociais diante de um envelhecimento demográfico: a importância de ressignificar o papel da família. Rev Bras Geriatr Gerontol,; 14(2), 353-363.

Manoel M. F., Teston, E. F., Waidman, M. A.P., Decesaro MN \& Marcon, S. S. (2013). As relações familiares e o nível de sobrecarga do cuidador familiar. Esc Anna Nery Rev Enferm. 17(2), 346-53.

Minatel, M. M. \& Matsukura, T. S. (2014). Famílias de crianças e adolescentes com autismo: cotidiano e realidade de cuidados em diferentes etapas do desenvolvimento. Ver. de Ter. Ocup. da Universidade de São Paulo, 25(2), p. 126.

Minayo, M. C. S. (2014). O desafio do conhecimento: pesquisa qualitativa em saúde. 14 ed. São Paulo: Hucitec.

Misquiatti, A. R., Brito, M. C. \& Assumpção, F. B. J. (2015). Sobrecarga familiar e crianças com transtornos do espectro do autismo: perspectiva dos cuidadores. Revista CEFAC, 17(1), 192-200. 
Mozzato A. R. \& Grzybovski D. (2011). Análise de Conteúdo como Técnica de Análise de Dados Qualitativos no Campo da Administração: Potencial e Desafios. RAC. 15(4), 731-747

Neves, E. T. \& Cabral, I.E. (2008). Empoderamento da mulher cuidadora de crianças com necessidades especiais de saúde. Texto \& Contexto Enferm, 17(3):552-560

Pinho, A. C. C., da Silva V. S. M., Souza A. M. \& Correa V. C. (2019). Sobre a forma de ocupar-se de cuidar de pessoas sob cuidados paliativos. Cad. Bras. Ter. Ocup., São Carlos, 27(1),118-126.

Pontes, A. C. A. (2008). Maternidade em mães de crianças com doenças neurológicas crônicas: um estudo sobre a sobrecarga e a qualidade de vida. (Tese de doutorado). Faculdade de Filosofia, Ciências e Letras, Universidade de São Paulo, São Paulo.

Rapoport, A., \& Piccinini, C. A. (2006). Apoio social e experiência da maternidade. Journal of Human Growth and Development, 16(1), 85-96.

Ribas, A. F. P., Junior R. C. R. \& Valente A. A. (2006). Bem-estar emocional de mães e pais e o exercício do papel parental: uma investigação empírica. Journal of Human Growth and Development, 16(3), 28-38.

Sales, E. (2003). Family burden and quality of life. Qual. Life Res., 12(1), S33-S41.

Silveira, A. D. \& Neves, E. T. (2012). Crianças com necessidades especiais em saúde: cuidado familiar na preservação da vida. Ciência, Cuidado e Saúde, 11.

Sprovieri, M. H. S. \& Assumpção Júnior, F. B. (2001). Dinâmica familiar de crianças autistas. Arq. Neuropsiquiatr., 59 (2)2, 230-237

Traub, L., Mengarda, C. F. (2016). Cuidador de familiar com câncer: papéis e necessidades. Psicologia.pt. 1646-6977.

Zamberlan, K. C. (2014). Cotidiano de cuidado da equipe de enfermagem às crianças com necessidades especiais de saúde hospitalizadas e suas famílias (Tese de mestrado). Universidade Federal de Santa Maria, Santa Maria, Rio Grande do Sul. 
